ISSN 1676-3742

\title{
O segredo de Francisco
}

Francis' secret

Marco Bartoli

\section{Resumo}

O cardeal Bergoglio, quando foi eleito pelos outros cardiais, escolheu chamar-se Papa Francisco. É um nome que não tinha antecedentes na história da Igreja. Esta escolha logo emocionou a todos: o papa tinha escolhido chamar-se com o nome do santo mais popular da história da Igreja Católica. Atrás deste nome devia estar uma ideia, um projeto, um segredo. A reflexão do Prof. Marco Bartoli propõe-se investigar a história e a vida de Francisco de Assis, para chegar a entender qual é o "segredo" do santo de Assis, que, ainda hoje, depois de oito séculos, é apresentado pelo Papa como um modelo para a Igreja de amanhã. A fonte mais segura para conhecer a intenção e a escolha de Francisco de Assis é o seu Testamento, isto é, o texto que ele escreveu nos últimos dias da sua vida para deixar aos seus irmãos, aos seus frades, a memória dos primeiros passos do seu caminho evangélico.

Palavras-chave: Francisco de Assis; evangelho; pobreza. 


\begin{abstract}
Cardinal Bergoglio, when he was elected by the other cardinals, chose to call himself Pope Francis, an unprecedented name in the history of the Church. This choice immediately touched everyone: the Pope had chosen to call himself by the name of the most popular saint in the history of the Catholic Church. Behind this name there must be an idea, a project, a secret. The reflection of Prof. Marco Bartoli intends to investigate the history and the life of Francis of Assisi, in order to come to understand the "secret" of the saint of Assisi, which today, after eight centuries, is presented by the Pope as a model for the Church of tomorrow. The most reliable source to understand the intent and the choice of Francis of Assisi is his Testament, which is the text he wrote in the last days of his life to leave for his brothers the memory of the first steps of his evangelical way.
\end{abstract}

Keywords: Francis of Assisi; Gospel; poverty.

\title{
Introdução
}

"E assim surgiu o nome no meu coração: Francisco de Assis. Para mim, é o homem da pobreza, o homem da paz, o homem que ama e preserva a criação; neste tempo, também a nossa relação com a criação não é muito boa, pois não? [Francisco] é o homem que nos dá este espírito de paz, o homem pobre... Ah, como eu queria uma Igreja pobre e para os pobres!"1

Com estas palavras, o papa Bergoglio explicava aos representantes da imprensa a escolha do seu nome - um nome que não tinha antecedentes na história da Igreja. Essa escolha logo emocionou a todos. O papa tinha escolhido chamar-se com o nome do santo mais popular da história da Igreja Católica. Atrás desse nome devia estar uma ideia, um projeto, um segredo. Qual é o segredo de Francisco?

Na história de Francisco de Assis, há algumas coisas que todos conhecem: que ele era um jovem rico e que podia tornar-se poderoso; mas que, ao contrário, deixou tudo e mudou completamente a sua própria vida.

\footnotetext{
${ }^{1}$ FRANCISCO, PP., Discurso. Encontro com os representantes dos meios de comunicação social (16/03/13). Disponível em <http://www.vatican.va/holy_father/francesco/speeches/2013/ march/documents/papa-francesco_20130316_rappresentanti-media_po.html>. Acesso em 26 de novembro de 2013.
} 
Uma das fontes mais antigas narra que: Francisco, o homem de Deus, alegre e confortado pelas palavras do bispo, levanta-se, entregando ao pai o dinheiro, e diz-lhe: "Senhor, quero devolver-lhe não somente o dinheiro que lhe pertence, mas também as roupas". Entrando num quarto, tira todas as suas vestes e colocando o dinheiro sobre elas, aparece nu, diante do bispo, do pai e de todos os presentes, e diz-lhes: "Ouçam todos e entendam: até agora chamei de pai a Pedro Bernardone, mas, como me propus servir a Deus, devolvo-lhe o dinheiro, que tanto o vem irritando, bem como todas as roupas, que dele recebi, pois de agora em diante quero dizer: Pai nosso que estais nos céus, e não pai Pedro Bernardone". Esta mudança foi um choque também para seus conterrâneos.

Levantando-se o pai, extremamente magoado e enfurecido, toma-lhe o dinheiro e todas as vestes. Enquanto Bernardone leva consigo tudo isso para casa, aqueles que tinham assistido à cena indignam-se contra ele, por não haver deixado ao filho nem mesmo um pano com que se cobrir. E movidos de compaixão começam a chorar sentidamente a sorte de Francisco.

As pessoas de Assis ficaram cheios de compaixão porque se aperceberam que o gesto do Francisco não era ditado por um desejo de ser original, como se fosse uma extravaância,; ao contrário, era um gesto que tinha uma coerência interior.

A mesma surpresa e o mesmo respeito encontram-se nas fontes, quando se fala de outros momentos mais famosos da vida de Francisco. Por exemplo, quando ele foi visitar o Sultão do Egito, que era o chefe do exército inimigo. Francisco foi lá visitá-lo com um companheiro, sem armas, sem nenhuma defesa.

No décimo terceiro ano de sua conversão foi para a Síria e, embora recrudescessem cada dia terríveis e duros combates entre cristãos e pagãos, não teve medo de se apresentar ao sultão dos sarracenos, levando um companheiro. Quem vai poder contar a coragem com que se manteve diante dele, a fortaleza com que falou, a eloquência e a confiança com que respondeu aos que insultavam a lei cristã? Preso pelos guardas antes de chegar ao sultão, não se assustou nem quando foi ofendido e açoitado; não recuou diante de suplícios e não ficou com medo nem da ameaça de morte. Foi maltratado por muitos que eram hostis e adversos, mas o sultão o recebeu muito bem: reverenciou Francisco quanto the foi possível e ofereceu-lhe muitos presentes, tentando convertê-lo para o espírito mundano. Porém, quando viu que ele desprezava valentemente todas as coisas como se não passassem de esterco, ficou admiradíssimo e olhava para ele como para um homem diferente. Ficou muito comovido com suas palavras e ouviu-o de muito boa vontade. ${ }^{2}$

${ }^{2} 1$ Cel., 57. 
A mesma coisa poderia se contar a propósito da sua morte. Sentindo já próximos seus últimos dias, em que a luz perpétua substituiria a luz que se acaba, demonstrou pelo exemplo de sua virtude que não tinha nada em comum com o mundo. Prostrado pela doença grave que encerrou todos os seus sofrimentos, fez com que o colocassem nu sobre a terra nua, para que, naquela hora extrema em que ainda podia enraivecer o inimigo, estivesse preparado para lutar nu contra o adversário nu. ${ }^{3}$

Também o gesto de ser colocado nu sobre a terra nua não era para Francisco ditado por um desejo de parecer original. Era um gesto que tinha uma coerência íntima, profunda. Francisco, mesmo nos momentos mais difíceis da sua vida, fazia coisas inusuais, diferente dos outros homens, mas todos percebiam que não eram gestos feitos só para serem vistos pelos outros; eram gestos que nasciam de uma exigência de íntima coerência. A única palavra que parece explicar esses gestos de Francisco é liberdade: os gestos de Francisco são gestos de um homem livre. Mas Francisco, como conseguiu tornar-se um homem livre?

\section{A liberdade no tempo de Francisco}

No tempo de Francisco, havia muitas maneiras de procurar a liberdade. Dante Alighieri dizia: "A nossa liberdade é o máximo dom que Deus atribuiu à natureza humana". Ao início do século XIII, podemos identificar três contextos históricos e culturais nos quais houve uma reflexão sobre a liberdade.

O primeiro contexto é aquele dos aristocráticos, dos cavaleiros. Esses cavaleiros estavam no topo da hierarquia social na Idade Média, segundo a tripartição típica daquela época: oratores, bellatores, laboratores. Eles eram os especialistas da guerra. Na tradição germânica somente os homens que podiam usar armas eram homens livres. Quando, no século XII, eles chegaram à cultura escrita, deram voz à sua ideia de liberdade. Duas ideias são muito importantes na literatura cortês e cavaleiresca: a ideia de aventura, e a ideia de liberalidade. A aventura é a atitude do cavaleiro que parte sem saber para onde vai e o que lhe pode acontecer amanhã. A aventura é o gosto de não ficar fechado num mundo pequeno, mas de pôr a própria vida ao serviço de algo de grande (como a procura do Graal). A liberalidade é o gosto de dar pelo prazer do dar. O cavaleiro devia mostrar a própria cortesia e gentileza através dos dons que só ele, enquanto rico, podia proporcionar.

${ }^{3} 2 \mathrm{Cel} 214$. 
Um segundo contexto é o dos mercadores. Havia um preconceito contra os mercadores. A igreja condenava a usura, isto é, o empréstimo a juros. Cada mercador era suspeito de ser usurário. A acusação contra eles era de serem avaros, isto é ávidos de ouro. O protótipo do mercador era Judas, o discípulo que vendeu o Senhor do mundo por trinta moedas. Apesar desse preconceito, os mercadores apresentavam-se como homens de grande humanidade: eles eram homens acostumados ao risco, que saíam do seu mundo pequeno para ir longe, até encontrar outras pessoas, outros povos, outras maneiras de viver. Foram eles que mudaram a ideia do tempo. Antes do século XIII, na Europa, o tempo era marcado pelos campanários das igrejas: era o tempo da oração; depois, foi marcado pelos campanários das torres do município: foi o tempo do trabalho. Um desses mercadores, que vivia no mesmo século de Francisco, na Itália, foi Marco Polo, que viajou até a China.

O terceiro contexto é o daqueles que hoje chamamos de intelectuais. No século XII, que é aquele imediatamente precedente ao do Francisco, nos arredores das igrejas catedrais, nas cidades mais importantes, surgiram escolas onde os magistri isto é os especialistas da palavra e do saber, começaram a receber um salário pago pelos seus alunos. Foi uma verdadeira revolução: o saber podia ser vendido exatamente como qualquer outra mercadoria. Quem possuísse o saber, podia com ele tornar-se rico. Em pouco tempo, estes especialistas formularam a própria ideia de liberdade, distinta daquela dos cavaleiros e dos mercadores, uma ideia que ainda hoje é central na reflexão sobre a liberdade.

Esses três contextos de reflexão sobre o tema da liberdade nascem todos numa nova realidade social e cultural: a das cidades. A sociedade medieval, até ao século XII, era principalmente uma sociedade rural (da qual os símbolos eram o mosteiro e o castelo). No século XII, as cidades europeias começaram a crescer e a aumentar a sua importância social e cultural. Um provérbio particularmente comum na região germânica dizia: "O ar da cidade liberta". Este não era somente um provérbio, porque as tradições jurídicas dos países germânicos permitiam a um servo que escapava do seu dono (quer fosse laico quer fosse eclesiástico) tornar-se um homem livre, se conseguisse viver numa cidade durante um ano e um dia. Em Assis, a cidade de Francisco, num documento de paz assinado em 1210, estava escrito: "qualquer pessoa venha a esta cidade em paz possa encontrar aqui segurança e salvação e possa aqui viver como homem livre".

Para compreender o percurso biográfico original de Francisco de Assis, é necessário conhecer essas ideias de liberdade presentes no seu tempo e na 
região onde ele vivia. Nesta perspectiva, podemos utilizar uma fonte biográfica que é a mais próxima aos acontecimentos de Assis - a legenda chamada "Legenda dos três companheiros". Nesta fonte lemos:

Já adulto e bem dotado, exerceu o ofício paterno, isto é, o comércio, mas de forma completamente diversa, pois era muito mais alegre e liberal do que ele. Vivia na boemia jogralesca, passeando de dia e de noite pela cidade de Assis, em companhia de amigos do mesmo temperamento, pródigo nos gastos e dissipando tudo o que tinha e ganhava em banquetes e festas e outras coisas supérfluas. ${ }^{4}$

Francisco era liberalior, muito mais liberal, isto é, mais generoso, mais pródigo no dar aos outros do que seu pai. Esta era uma característica da cultura cavaleiresca: a liberalidade, o gosto de dar pelo gosto do dar. Francisco era filho dum mercador, mas queria viver como um cavaleiro. Ele conhecia os atos dos cavaleiros através da literatura cavaleiresca. O seu laço com o modo de pensar dos cavaleiros é mostrado pela mesma fonte em uma página pouco depois:

Durante a guerra entre Perusa e Assis, Francisco, com muitos de seus concidadãos, foi aprisionado e encarcerado em Perusa; mas, como era nobre em costumes, foi colocado como prisioneiro entre os cavaleiros. Certo dia, estando seus companheiros de prisão dominados de profunda tristeza, ele, que era de natural sorridente e jovial, não se mostrava abatido, mas alegre. Por isso, um dos companheiros chamou-o de louco, porque se alegrava mesmo estando na prisão. Francisco respondeu-lhe em tom convicto: "O que pensais de mim? Ainda serei venerado pelo mundo inteiro". Como um dos soldados tivesse injuriado a um companheiro e, por este motivo, todos dele queriam afastar-se, só Francisco não lhe negou a amizade e exortou aos outros a fazerem o mesmo. Passado um ano, restabelecida a paz entre as cidades mencionadas, Francisco voltou com seus companheiros para Assis. ${ }^{5}$

A coisa mais interessante nesta página é que nela não há nenhuma referência a um vocabulário religioso: fala-se de um jovem que, apesar de ser filho de um mercador, tinha maneiras de viver corteses. Ele, depois de ter participado numa guerra (como acontecia frequentemente), foi colocado

\footnotetext{
${ }^{4}$ 3Comp 2.

${ }^{5} 3$ Comp 4.
} 
numa prisão junto com os "grandes", isto é, com os aristocratas da sua cidade, e foi aí que ele revelou toda a sua ambição: "O que pensais de mim? Ainda serei venerado pelo mundo inteiro". Com certeza, os leitores da legenda sabiam o que veio a acontecer depois e que Francisco seria proclamado santo e, por isso, venerado em todo o mundo, mas, ao momento dos acontecimentos narrados, este aspecto religioso fica escondido, o que se vê é somente um jovem que desejava ser admirado no mundo inteiro.

Uma segunda coisa interessante nesta página é que Francisco é apresentado como "já adulto e bem dotado". Isto significa que ele já não era um rapazinho. A sua liberalidade não era um jogo de rapazes; era uma escolha cultural específica: a escolha de partilhar a cultura dos aristocratas, o modelo cultural dos cavaleiros. De família, mercador; de cultura, cavaleiro. Assim Francisco queria se apresentar aos outros.

A Legenda dos Três Companheiros apresenta-nos Francisco como um jovem adulto, "expert" no "ofício paterno do comércio". Para ter uma ideia dos preconceitos contra os mercadores como Francisco, é possível ler as palavras que o bispo de Assis, segundo a mesma legenda, disse a Francisco, para convencê-lo a restituir os bens do seu pai: "Teu pai está muito irritado e escandalizado contigo. Por isso, se queres servir a Deus, devolve-lhe o dinheiro que tens. Deus não quer que o empregues em obras da Igreja, por ter sido ganho talvez com fraudes e por causa dos pecados de teu pai". ${ }^{6}$ Um mercador era sempre suspeito de ter ganho os seus bens com fraudes.

Francisco, filho de um mercador, um comerciante, desejava viver como um cavaleiro e, por isso, começou a sua busca. Nasceu assim a sua aventura. Ele já tinha experimentado pessoalmente a liberdade do comerciante, do mercador; ele procurou com paixão a liberdade do cavaleiro, tentando de viver os ideais da cavaleria desde a sua juventude. Ele foi muito menos atraído pelo ideal de liberdade dos intelectuais. Nos anos seguintes, continuaria a chamar-se de simples e iletrado; ele nunca procurou a sua liberdade através do estudo, mas os ideais de liberdade dos "magistri" permanecem interessantes para nós, porque, logo depois da morte de Francisco, foram esses que interpretaram a sua vida e tentaram explicar a sua liberdade. O tema da liberdade é certamente central na filosofia escolástica franciscana.

Contudo, há uma coisa em comum entre as ideias de liberdade dos cavaleiros e aquela dos mercadores ou a dos intelectuais: a ideia de que a liber-

\footnotetext{
${ }^{6} 3$ Comp 19.
} 
dade encontra-se quando a gente se distingue dos outros, quando a gente sai da multidão, quando se torna especial. Francisco também tinha experimentado essa perspectiva, mas, a certa altura, ele encaminhou-se por uma estrada diferente.

\section{A escolha de Francisco}

Como conseguiu Francisco tornar-se um homem livre? As antigas biografias narram diferentes momentos da sua vida nos quais houve mudanças importantes. Porém, sobre um assunto de tão grande importância, é fundamental dar a precedência a um texto que é justamente famoso: o Testamento do próprio Francisco. Neste escrito que Francisco ditou nos últimos dias da sua vida ele lembrou os primeiros passos da sua caminhada, com estas palavras:

Foi assim que o Senhor concedeu a mim, Frei Francisco, iniciar uma vida de penitência: como estivesse em pecado, parecia-me deveras insuportável olhar para leprosos. O Senhor mesmo me conduziu entre eles e eu tive misericórdia para com eles. Enquanto me retirava deles, justamente o que antes me parecia amargo se me converteu em doçura da alma e do corpo. E depois disto demorei só bem pouco e abandonei o mundo. ${ }^{7}$

Para Francisco, a mudança fundamental da sua vida está ligada a um encontro, mas não o encontro com um homem espiritual ou sábio, com alguém que poderia dar uma orientação a sua vida, não: mas a um encontro com alguns leprosos que viviam nos arredores de Assis.

O Testamento, como dizemos, é uma re-leitura da vida de Francisco, uma leitura teológica. O protagonista daquelas suas primeiras linhas não é Francisco, mas é o Altíssimo. Francisco, ao final da sua vida, reconhece que o seu encontro com os leprosos foi fruto da iniciativa de Deus: "o Senhor mesmo me conduziu entre eles".

Esta inciativa de Deus, no entanto, não devia ser evidente na altura do encontro. Pode-se dizer que Francisco e os leprosos tinham dois destinos diferentes e que eles nunca deveriam se encontrar. Francisco era jovem, saudável e rico, e ele podia tornar-se poderoso; os leprosos eram doentes, pobres e, antes de tudo, deprezados.

A condição dos leprosos na Itália central do século XIII era caracterizada pelo prejuizo e pela segregação. Os fundamentos para esta segregação

${ }_{7}$ Testamento 1-3. 
se encontravam, principalmente, na Bíblia. No livro do Levítico está escrito: Quem for declarado leproso deverá andar com as roupas rasgadas e despenteado, com a barba coberta, e gritando: "Impuro! Impuro!" Ficará impuro enquanto durar sua doença. Viverá separado e morará fora do acampamento. ${ }^{8}$

Os estatutos das cidades italianas utilizaram dispositivos parecidos: os leprosos eram impuros, isto é, eram contagiosos e, por isso, tinham que ficar longe das cidades, longe das pessoas saudáveis, longe da gente "normal". $\mathrm{Na}$ Idade Média, pensava-se que a lepra se contagiava por via sexual, o que significava que os leprosos eram doentes porque antes eles teriam tido uma maneira de viver desordenada e imoral. A lepra era o sinal do seu pecado. Os leprosos eram desprezados duas vezes: porque eram pobres e doentes, mas também porque pecadores.

Quando Francisco escreve no seu Testamento: "parecia-me deveras insuportável [amargo] olhar para leprosos" [nimis mihi videbatur amarum videre leprosos], explica um sentimento que não era somente o seu, mas aquele de toda gente. A visão dos leprosos era uma coisa amarga para todos. É por isso que o encontro entre Francisco e os leprosos não era uma coisa normal.

Mas Francisco "teve" misericórdia para com eles. A misericórdia, nas palavras de Francisco, é algo de concreto, algo para fazer. Francisco provavelmente deu uma esmola, ou, talvez, curou as suas pragas, ou lhes deu um abraço de paz. Ele fez algo de concreto para com eles. Os sentimentos vieram depois. No início, a misericórdia é uma coisa concreta. Só depois de tudo isso, aquele encontro tornou-se para Francisco uma doçura: "o que antes me parecia amargo se converteu em doçura da alma e do corpo".

A lembrança termina com uma frase pequena: "E depois disto demorei só bem pouco e abandonei o mundo". "Abandonar o mundo" era a maneira tipica do vocabulário monástico para explicar a mudança de vida dos monges: eles saíam da cidade para ir ao deserto o à floresta para viver uma vida diferente. Só que Francisco nunca entrou num mosteiro, nunca se retirou num deserto. Ele continuou a viver perto das cidades, no meio das pessoas. Porque ele utilizou essa expressão? Para dizer que o encontro com os leprosos foi o encontro decisivo na sua escolha de mudar radicalmente a sua vida.

O texto do Testamento de Francisco precisa ainda de uma explicação. A página que lemos termina com as palavras: "E depois disto demorei só bem pouco e abandonei o mundo". A pergunta que surge é: porque é que Francisco

${ }^{8}$ Lev $21,45-46$. 
esperou ainda um pouco antes de mudar completamente a sua vida? O que aconteceu entre o encontro com os leprosos e a escolha definitiva de mudar a sua vida? A resposta a esta pergunta se encontra numa fonte que aparece nos anos 40 do século XIII, isto é, 15 anos depois da morte de Francisco. Trata-se da Legenda dos três companheiros, onde está escrito:

Poucos dias depois, passando perto de São Damião, o Senhor inspirou-o para que visitasse aquela igreja e orasse. Entrando, pôs-se em fervorosa oração diante da imagem de um Crucifixo, o qual, piedosa e benignamente, falou-lhe: Francisco, não vês que a minha casa está em ruínas? Vai, pois, e restaura-a para mim. Trêmulo e atônito, disse: Com muito boa vontade o farei, Senhor. Entendeu que Cristo falava daquela igreja de São Damião que, por ser muito antiga, ameaçava cair de um momento para o outro. ${ }^{9}$

O Papa Francisco, na sua recente visita a Assis, sublinhou a importância deste encontro de Francisco com o Crucifixo.

Onde começa o caminho de Francisco para Cristo? Começa do olhar de Jesus na cruz. De deixar-se olhar por Ele no momento em que dá a vida por nós e nos atrai para Ele. Francisco fez esta experiência, de um modo particular, na pequena igreja de São Damião, rezando diante do crucifixo, que poderei também eu venerar hoje. Naquele crucifixo, Jesus não se apresenta morto, mas vivo! O sangue escorre das feridas das mãos, dos pés e do peito, mas aquele sangue exprime vida. Jesus não tem os olhos fechados, mas abertos, bem abertos: um olhar que fala ao coração. E o Crucifixo não nos fala de derrota, de fracasso; paradoxalmente, fala-nos de uma morte que é vida, que gera vida, porque nos fala de amor, porque é o Amor de Deus encarnado, e o Amor não morre, antes derrota o mal e a morte. Quem se deixa olhar por Jesus crucificado fica recriado, torna-se uma "nova criatura". ${ }^{10}$

Sim, entre o encontro com os leprosos e a escolha de abandonar definitivamente o mundo, houve para Francisco uma experiencia especial em frente do crucifixo de São Damião. Justamente a Legenda dos três companheiros termina esta página dizendo: "Por estas palavras, ficou repleto de tanto contentamento e tão iluminado, que sentiu verdadeiramente em sua alma a presença de Cristo crucificado que lhe havia falado".

\footnotetext{
${ }^{9}$ 3Comp. 13.

${ }^{10}$ FRANCISCO, PP., Homilia na Praça de São Francisco, Assis, 4 de Outubro de 2013.
} 
Francisco reparou a pobreza daquele homem crucificado: a igreja estava em ruínas, o teto podia cair, nem tinha uma luz por baixo da imagem. Sim, aquele homem crucificado era parecido com os leprosos que Francisco acabava de visitar: sem abrigo, sem luz, sem proteção. Pode-se dizer que foi o encontro com os leprosos que preparou o encontro com o crucifixo: quantas vezes Francisco antes daquele dia deveria ter visto imagens do Cristo em cruz! Somente depois do seu encontro com os pobres leprosos ele percebeu que aquele homem em cruz era verdadeiramente pobre. Porém, pode-se dizer também que foi o encontro com o crucifixo que explicou a Francisco o valor dos seus encontros com os pobres leprosos: foi depois deste encontro em São Damião que ele pôde dizer que foi o Altíssimo que o conduziu no meio dos leprosos.

\section{Francisco depois da sua conversão}

A liberdade nunca é o fruto de uma mudança súbita. Depois dos encontros com os leprosos e com o crucifixo, tudo mudou para Francisco, no sentido de que ele tomou caminho novo. Porém, ele ainda não sabia para onde este caminho conduzia. Há um tempo de incerteza, não somente antes, mas também depois da conversão de Francisco. Foram três anos, durante os quais Francisco ficou sozinho. Foram anos difíceis durante os quais Francisco experimentou o cansaço da procura da liberdade.

Mais uma vez podemos ler um testemunho destes momentos difíceis numa página da Legenda dos três companheiros:

Após a visita aos leprosos e tendo ele mudado, para melhor, conduzindo a lugares afastados um certo companheiro, a quem muito queria, dizia-lhe que havia encontrado um grande e precioso tesouro. Alegrou-se muito aquele homem, e de boa vontade o acompanhava sempre que chamava. Francisco o levava muitas vezes a uma caverna perto de Assis, e, nela entrando sozinho, deixava do lado de fora o companheiro, desejoso de possuir o tesouro; e, assim, tomado de um novo e singular espírito, orava ao Pai, às escondidas, cuidando que ninguém soubesse o que estava fazendo lá dentro, a não ser Deus, a quem assiduamente consultava sobre como possuir o tesouro celeste. Vendo isto, o inimigo do gênero humano tentava desviá-lo do bom caminho que havia empreendido, incutindo-lhe temor e horror. Havia em Assis uma mulher enormemente corcunda e o 
demônio, aparecendo ao homem de Deus, trazia-lhe à mente e ameaçava transferir para ele a gibosidade daquela mulher, se não desistisse do propósito de conversão. ${ }^{11}$

A tentação, nesse caso, representa simplesmente a projeção do medo interior do próprio Francisco: o medo do contágio dos pobres. Como se o diabo lhe dissesse: "Se você não para de acompanhar os leprosos, você será julgado como você julgava aquela mulher deforme quando você era mais jovem e a encontrava nas estradas de Assis". O medo de se aproximar dos pobres é o medo do contágio e do preconceito: o medo de ser mal julgado, como são mal julgados os pobres.

\section{Conclusão}

Talvez nós pensemos que para os santos tudo deveria ser fácil, porque eles eram santos, mas esta legenda nos explica que, para Francisco, mesmo depois da escolha de mudar a sua vida, não foi tudo fácil; ele teve que ultrapassar os seus próprios medos. É como é explicado na Legenda dos Três Companheiros:

Mas o fortíssimo soldado de Cristo, desprezando as ameaças diabólicas, orava a Deus para que guiasse seus passos. Atormentava-o uma grande ansiedade de espírito. E não haveria de sossegar, enquanto não visse realizados os sonhos que o faziam sofrer a todo instante duramente. Vivia inflamado, interiormente, de um fogo divino. Não conseguindo ocultar o calor na mente, arrependia-se de haver pecado tão gravemente e já não lhe agradavam os males passados ou presentes, pois não tinha alcançado ainda a capacidade de dominar-se com relação às coisas futuras. Por isso, ao sair da caverna, aparecia ao seu companheiro transformado em outro homem. ${ }^{12}$

Sim, Francisco aparecia transformado em outro homem, porque se ia libertando do medo do encontro com os mais pobres e os mais fracos. Foi assim que ele aprendeu a arte da amizade, a arte do encontro com todos. Foi assim que ele pensou em poder encontrar até o Sultão, o chefe dos inimigos da cristandade. Mas foi também graças a esta arte da amizade que ele aprendeu

\footnotetext{
${ }^{11}$ 3Comp. 12.

${ }^{12}$ Idem.
} 
a escutar os mais pequenos, quando se aproximavam dele. Foi assim que Francisco tornou-se "pequeno irmão universal" irmão de todos os homens.

Podemos voltar à ideia de liberdade: Francisco partilhou a ideia de liberdade dos mercadores e dos cavaleiros; como eles, pensou em procurar a sua liberdade em se distinguir dos outros, em parecer melhor do que os outros. Só que, depois do seu encontro com os leprosos e com o Crucifixo, ele compreendeu que havia um outro caminho para a liberdade: o do encontro com os outros. E, assim, encontro após encontro, Francisco tornou-se cada vez mais humano e cada vez mais livre, até chegar a ser "irmão de todos, irmão universal".

Acho que este seja o segredo do Francisco de Assis, mas também acho que este seja o segredo do papa Francisco.

Marco Bartoli

Professor associado de história da Idade Media Presidente do Curso de licenciatura em ciências da educação e da formação da Universidade LUMSA de Roma Professor de história do franciscanismo Pontificia Universidade "Antonianum" - Roma, Itália E-mail: mbartoli54@gmail.com

Recebido em 11/11/13 Aprovado em 12/11/13 